\title{
HAEMATOLOGICAL AND BIOCHEMICAL OBSERVATIONS DURING A 750 MILE RELAY
}

\author{
C. R. NYMAN, MB, MRCP(UK)
}

Pilgrim Hospital, Boston, Lincolnshire

\section{ABSTRACT}

During a marathon relay from John $0^{\prime}$ Groats to Lands End (JOGLE) various blood and urine parameters were measured in the runners. Samples of blood and urine were taken from each runner immediately prior to the event and on two occasions during it. Subsequently a three point plot was made for each parameter measured. No special diet was taken. Food and liquid refreshment was provided during the run, the first two days of which came from the organisers. The total distance covered was 870 miles and the time taken one hundred hours and thirty-two minutes. Although the results do not approach statistical significance a trend has been shown suggesting that even with the modern running shoe injury may still occur.

\section{METHODS}

\section{Subjects}

Twenty fit adults accustomed to long distance running participated in the event. They were split into two groups of ten runners, each group responsible for running in relay. fashion for a 12 hour period each day, the subsequent 12 hour period being used for rest, feeding and transportation to the next hand-over point. Each runner therefore was expected to run a leg of one hour twelve minutes. The distance covered during this time ranged from eight to twelve and a half miles with an average of ten miles. The twenty runners consisted of seventeen men and three women with ages ranging from seventeen years to forty-eight years. Their athletic capabilities varied from those able to run marathons in two and a half hours to four hours. A minimum weekly mileage of $\mathbf{3 5}$ miles in training was regarded as mandatory for each runner. They all received a full medical examination. Originally 25 subjects were examined, but any runner with a present or past history of cardiovascular or severe respiratory disorder was excluded. Five runners were subsequently rejected, two because of seasonal asthma, one with chest discomfort subsequently shown to have hypertrophic obstructive cardiomyopathy and two in whom the weekly mileage was less than 30 .

\section{Measurements}

All runners received a chest $X$-ray, electrocardiogram (ECG) and a respiratory function test using a vitalograph and peak flow meter. The ECG's and chest X-rays were interpreted by two independent observers of Consultant status. One of the runners demonstrated diffuse $T$ wave inversion in the anterior chest leads on his ECG and was subjected further to a cardiac stress test and an echocardiogram. Both these tests were normal. A full blood count, plasma viscosity, blood urea and electrolytes, liver function tests, blood sugar and haptoglobulins (Anderson et al, 1966) were measured on each runner along with urine estimations of free haemoglobin, protein, haemosiderin (Crosby and Dameshek, 1951) and culture. A second sample of blood and urine was taken from each runner at Lancaster and analysed at the Lancaster Royal Infirmary. This was approximately 300 miles into the marathon. A further and final set of blood and urine samples were taken from each runner in Exeter and analysed at the Royal Devon and Exeter Hospital, the distance covered at this point being approximately 750 miles. Peak flow measurements were taken from each runner before and after running their legs. All tests and results were subsequently calibrated and checked in the Pathology Department of the Pilgrim Hospital in Boston.

\section{RESULTS}

On reaching John O'Groats one of the male runners withdrew from the squad because of family illness. This reduced the complement of runners to 19 and of necessity increased each runner's daily mileage. Each now ran for 76 minutes per day and covered an average distance of 10.5 miles. Tabulated (Table 1) are the ages of the 19 runners with their requisite biochemical results measured on the three occasions. The serum sodium, blood sugar, blood bicarbonate and creatine remained normal throughout the whole of the run. The blood urea was normal in most runners before the onset of the run but become elevated in all runners subsequently except for

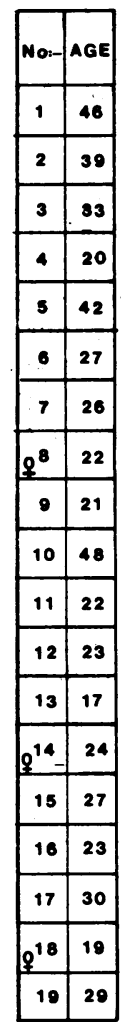

\begin{tabular}{|c|c|c|c|c|c|c|c|c|c|c|c|c|c|c|}
\hline \multicolumn{3}{|c|}{$\begin{array}{c}\text { BILIRUBIN } \\
2-17 \mu \mathrm{molg} / \mathrm{L}\end{array}$} & \multicolumn{3}{|c|}{$\begin{array}{l}\text { S.G.P.T } \\
\langle 40 \mathrm{U} / \mathrm{L}\end{array}$} & \multicolumn{3}{|c|}{$\begin{array}{l}\text { S.G.0.T } \\
<40 \mathrm{U} / \mathrm{L}\end{array}$} & \multicolumn{3}{|c|}{$\begin{array}{c}\text { UREA } \\
2.5-7.5 \mathrm{mmole}\end{array}$} & \multicolumn{3}{|c|}{$\begin{array}{l}\text { LLKALINE PQ } \\
34-104 \mathrm{U} / \mathrm{L}\end{array}$} \\
\hline 7 & 2 & 3 & 1 & 2 & 3 & 1 & 2 & 3 & 1 & 2 & 3 & 1 & 2 & 3 \\
\hline 14 & 16 & 264 & 16 & 23 & 24 & 18 & $54^{*}$ & 39 & $5.7 \mathrm{k}$ & $10.1 \%$ & 11.80 & 95. & 95 & 82 \\
\hline 8 & 13 & 15 & 16 & 24 & 24 & 28 & 33 & 35 & 7.1 & 4.6 & 6.2 & 26 & 29 & 30 \\
\hline 14 & 19** & 16 & 24 & 21 & 24 & 33 & $55^{*}$ & $42^{*}$ & 8.14 & 8.5 & $9.5{ }^{4}$ & 61 & 54 & 61 \\
\hline 12 & 112 & 106 & 7 & 21 & 12 & 23 & 33 & 36 & 6.0 & 5.9 & $8.0 *$ & 50 & 77 & 72 \\
\hline 22 & 11 & 9 & 12 & 35 & 28 & 22 & 31 & 41* & 7.7 & 6.4 & 7.2 & 79 & 61 & 66 \\
\hline 7 & 14 & 9 & 16 & 22 & 26 & 20 & 37 & 46" & 3.9 & 4.8 & 6.2 & 60 & 60 & 64 \\
\hline 9 & 12 & 15 & 8 & 17 & 15 & & 10 & $49^{\circ}$ & 6.5 & 5.6 & $8.5 "$ & 66 & 47 & 59 \\
\hline 10 & 11 & 25 & 23 & $25 *$ & 24 & 21 & 27 & \begin{tabular}{|l|}
31 \\
\end{tabular} & 4.3 & 7.2 & 5.7 & 57 & 46 & 43 \\
\hline $10^{*}$ & 13 & & 25 & 29 & 20 & 29 & $79^{*}$ & $53^{\circ}$ & 4.6 & 5.6 & 6.6 & 51 & 24 & 51 \\
\hline 9 & 26 & 25 & 22 & 37 & 27 & 26 & $60 *$ & 38 & 7.7 & 11.9f & $9.0 *$ & 64 & 70 & 63 \\
\hline 12 & 12 & 15 & 12 & 7 & 6 & 24 & 21 & 29 & 3.9 & 5.2 & 6.1 & 91 & 76 & 67 \\
\hline 19 & 25* & 25. & 22 & $42^{\circ}$ & 35 & 39 & 105* & $84^{4}$ & 5.1 & 6.1 & 6.0 & 59 & 69 & 62 \\
\hline 11 & 18* & 27 & 19 & $43^{*}$ & 29 & 27 & $77^{*}$ & $51 *$ & 3.8 & 6.4 & 6.8 & 254. & 297 & 182 \\
\hline 21 & 7 & 9 & 16 & 49* & 30 & 26 & $131^{*}$ & $102^{*}$ & 4.6 & 3.1 & 3.8 & 61 & 56 & 52 \\
\hline 10 & 9 & 14 & 23 & 23 & 20 & 29 & 23 & 30 & 4.1 & 5.4 & 8.0*| & 62 & 87 & 68 \\
\hline 10 & 13 & 17 & 11 & 38 & 30 & 30 & $100^{*}$ & $95^{\circ}$ & 5.2 & 3.1 & 3.2 & 55 & 51 & 47 \\
\hline $25^{*}$ & 25 & 46 & 21 & 29 & 30 & 23 & 29 & $41 *$ & 6.3 & 5.0 & $7.7 *$ & 63 & 54 & 53 \\
\hline 12 & 8 & 14 & 24 & 24 & 12 & 23 & 25 & 23 & 6.0 & 5.5 & 7.0 & 82 & 55 & 46 \\
\hline $35 *$ & $37^{*}$ & 600 & & $53^{\circ}$ & 640 & 25 & $205^{\circ}$ & 2390 & 6.0 & 7.0 & 10.2 & 60 & 55 & 58 \\
\hline
\end{tabular}

table. 1. LiVER function tests on the three daYs for the NUMBERED SUBJECTS

- -signifies an abnormal result

subjects 14 and 16 . The haemoglobin and haptoglobin results are charted in Figs. 1 and 2. During this event two of the runners were troubled with shortlived diarrhoea, one suffered a 24 hour spell of nausea and vomiting, another (Subject 4) ran with a torn calf muscle which occurred during the first day's run and finally and as subsequently transpired Subject 19 ran with a stress fracture of the fibula. The last two runners demonstrated an elevated white cell count on the second and third estimations. The white cell counts of all the other runners were normal on all three samples. The results were analysed using a Students $T$ test and a three point plot made for each parameter measured from each runner. The peak flow measurements showed no significant change for each runner throughout the whole of the running period.

From Fig. 2 it is apparent that only five of the nineteen runners had normal baseline haptoglobin levels. In fifteen of the runners the levels fell progressively during the run (also noted by Davidson in 1969) but rather surprisingly in Subjects $3,7,10$ and 11 the final level is higher than at the start. All the baseline haemoglobin levels were normal though one of the female runners became mildly anaemic during the event with a haemoglobin falling by 2 grams to 11.5 grams. This was not due to menstruation. However in other runners the trend was for the haemoglobin level to rise initially in the second sample only to fall subsequently back to the pre-run level in the third sample. This was reflected by a similar chang change in haematocrit. Biochemically the liver function tests 

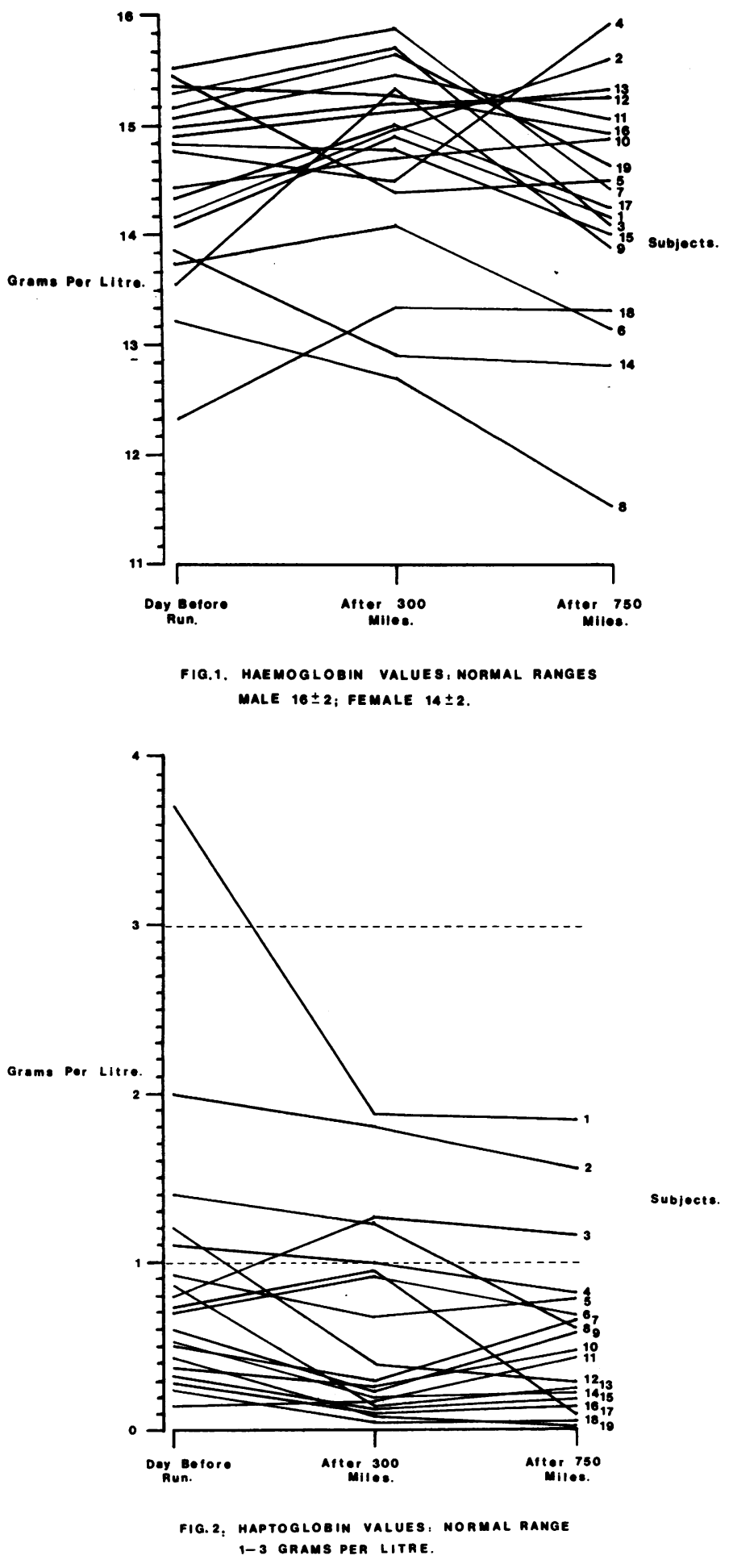

became markedly disturbed in some subjects and by comparing Fig. 2 with Table I, it can be seen that the greater changes occur in those runners in whom the haptoglobin fell the most. All the urine estimations were normal and cultures sterile.

\section{DISCUSSION}

One of the most important points to realise is that during the period of the run the athletes lived an abnormal existence taking food and liquid refreshment plus sleep whenever the opportunity was available. Of necessity this made for an enjoyable trip with a great deal of camaraderie but it did mean that as the days passed the runners became more fatigued and were running under less ideal circumstances. However accepting this, I believe three points can be made:
1. The serum haptoglobins were abnormal in a great number of runners prior to the event. During the relay the haptoglobins continued to fall in the majority of runners (Davidson, 1969). There was also a rise in the bilirubin and the liver enzymes became deranged. There appears to be quite a close correlation between the fall in haptoglobulins and the disturbance of liver function tests suggesting this to be more likely related to haemolysis rather than liver dysfunction. No comparison was made between the initial level of haptoglobin and the weekly mileage for each runner, nor was any consideration taken into account of the different types of running shoe used. However Subjects 9,12 and 19 showed the greatest disturbances in liver function tests and haptoglobins and all trained and ran in shoes poorly designed for road running. I feel further study is needed here.

2. The rise in blood urea during the relay with a normal serum creatinine throughout supported by a rise in haemoglobin and haematocrit is very suggestive of dehydration. This occurred in most of the runners. However none of the runners came to any grief because of this and all the abnormal results subsequently returned to normal after the event. No abnormalities were found in the urine samples of any of the runners.

3. Subject 13 also demonstrated a high serum alkaline phosphatase as well as other disturbed liver function tests. The serum alkaline phosphatase was elevated in all three samples and $I$ believe this to be due to the subject's age of 17 and the fact that he was still completing his pubertal growth spurt. I therefore feel this abnormally high parameter to be a physiological phenomenon related to bone growth rather than to a pathological one due to liver dysfunction.

Although these results do not approach statistical significance an important trend has been demonstrated. With larger numbers of runners and more estimations a statistically significant result could be obtained. I believe these results demonstrate ongoing haemolysis in runners participating in long distance (endurance) events. Although there is no actual fall in haemoglobin level there was a rise in bilirubin and a fall in haptoglobins in a large number of runners, even in those wearing the most modern and sophisticated of running shoes. However the changes were most marked in Subject 19 who trained and ran in plimsolls. It is known that in severe cases of haemolysis haemoglobinuria may occur (Ham, 1958) and in the most severe examples renal damage may result (Barry and Crosby, 1963). In this very simple study I believe that I have demonstrated a degree of continuing haemolysis in runners participating in endurance events and that further study is needed to elucidate this further with the aim of moving towards a running shoe which ideally eliminates this problem or at least minimises it.

\section{ACKNOWLEDGEMENTS}

I wish to extend my thanks to the Pathology Department in the Pilgrim Hospital, Boston, the Lancashire Royal Infirmary and the Royal Devon and Exeter Hospital without which the analysis of our samples would not have been undertaken. I would also like to thank all the runners for not only participating in the event but agreeing to give freely blood and urine samples in the interest of health in sport.

\section{References}

Anderson, M. N., Mouritzen, C. V. and Gabrieli, E., 1966 "Mechanisms of plasma haemoglobin clearance after acute haemolysis". Ann.Surg. 163: 529 .

Barry, K. G. and Crosby, W. H., 1963 "The prevention and treatment of renal failure following transfusion reaction". Transfusion 3: 34 .

Crosby, W. H. and Dameshek, W., 1951 "The significance of haemoglobinaemia and associated haemosiderinuria, with particular reference to various types of haemolytic anaemia". J.Lab.clin.Med. 38: 829.

Davidson, R. J. L., 1969 "March or exertional haemoglobinuria". Seminars in Haematol. 6: 162

Ham, T. H., 1955 "Haemoglobinuria". Amer.J.Med. 18: 990. 